\title{
UNIVERSITYOF BIRMINGHAM

\section{Working within an Individual Zone of Optimal Functioning (IZOF) framework: Consultant practice and athlete reflections on refining emotion regulation skills \\ Woodcock, C; Cumming, Jennifer; Duda, Joan; Sharp, LA}

DOI:

10.1016/j.psychsport.2011.11.011

Document Version

Early version, also known as pre-print

Citation for published version (Harvard):

Woodcock, C, Cumming, J, Duda, J \& Sharp, LA 2012, 'Working within an Individual Zone of Optimal

Functioning (IZOF) framework: Consultant practice and athlete reflections on refining emotion regulation skills',

Psychology of Sport and Exercise, vol. 13, no. 3, pp. 291-302. https://doi.org/10.1016/j.psychsport.2011.11.011

Link to publication on Research at Birmingham portal

\footnotetext{
General rights

Unless a licence is specified above, all rights (including copyright and moral rights) in this document are retained by the authors and/or the copyright holders. The express permission of the copyright holder must be obtained for any use of this material other than for purposes permitted by law.

-Users may freely distribute the URL that is used to identify this publication.

- Users may download and/or print one copy of the publication from the University of Birmingham research portal for the purpose of private study or non-commercial research.

- User may use extracts from the document in line with the concept of 'fair dealing' under the Copyright, Designs and Patents Act 1988 (?)

- Users may not further distribute the material nor use it for the purposes of commercial gain.

Where a licence is displayed above, please note the terms and conditions of the licence govern your use of this document.

When citing, please reference the published version.

Take down policy

While the University of Birmingham exercises care and attention in making items available there are rare occasions when an item has been uploaded in error or has been deemed to be commercially or otherwise sensitive.

If you believe that this is the case for this document, please contact UBIRA@lists.bham.ac.uk providing details and we will remove access to the work immediately and investigate.
} 
Provided for non-commercial research and education use. Not for reproduction, distribution or commercial use.

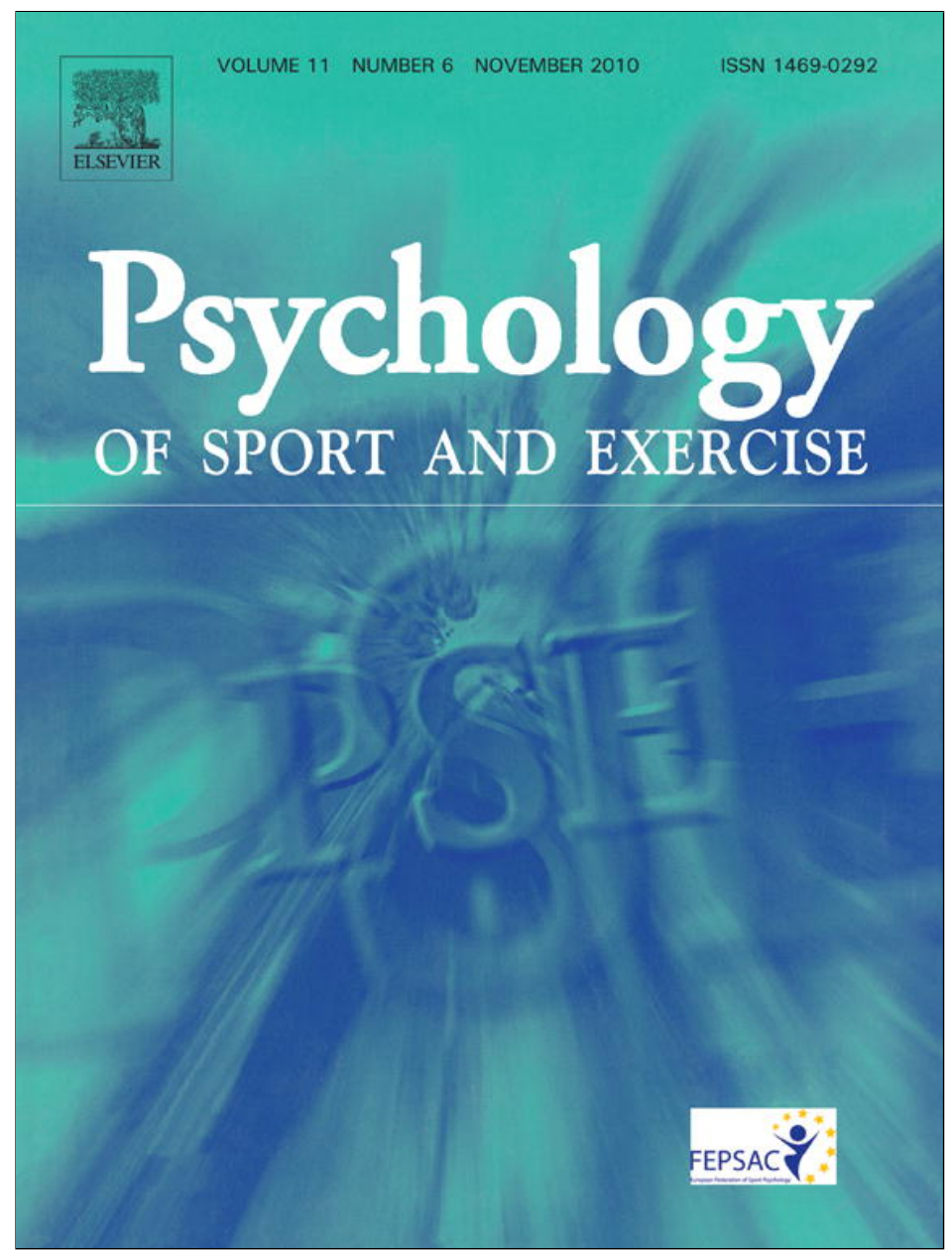

(This is a sample cover image for this issue. The actual cover is not yet available at this time.)

This article appeared in a journal published by Elsevier. The attached copy is furnished to the author for internal non-commercial research and education use, including for instruction at the authors institution and sharing with colleagues.

Other uses, including reproduction and distribution, or selling or licensing copies, or posting to personal, institutional or third party websites are prohibited.

In most cases authors are permitted to post their version of the article (e.g. in Word or Tex form) to their personal website or institutional repository. Authors requiring further information regarding Elsevier's archiving and manuscript policies are encouraged to visit:

http://www.elsevier.com/copyright 


\title{
Working within an Individual Zone of Optimal Functioning (IZOF) framework: Consultant practice and athlete reflections on refining emotion regulation skills
}

\author{
Charlotte Woodcock $^{\mathrm{a}, *}$, Jennifer Cumming ${ }^{\mathrm{a}}$, Joan L. Duda ${ }^{\mathrm{a}}$, Lee-Ann Sharp ${ }^{\mathrm{b}}$ \\ ${ }^{a}$ School of Sport and Exercise Sciences, University of Birmingham, Edgbaston, Birmingham B15 2TT, UK \\ ${ }^{\mathrm{b}}$ University College Plymouth St Mark \& St John, UK
}

\section{A R T I C L E I N F O}

\section{Article history:}

Received 13 April 2011

Received in revised form

21 November 2011

Accepted 24 November 2011

Available online 7 December 2011

\section{Keywords:}

Sport psychology

IZOF

Professional practice

Emotion regulation

Applied practice

\begin{abstract}
A B S T R A C T
Objective: To examine how working within Hanin's (2000a) Individual Zone of Optimal Functioning theoretical model (IZOF) informs intervention development for enhancing athletes' emotion regulation skills.

Design: A single case study design was adopted to examine the applied process of facilitating a female university cross-country runner's emotion regulation skills.

Method: Consultant reflections followed Boud's (2001) reflective learning model for immediate and delayed reflection that informed an action research narrative organized round Kellmann and Beckmann's (2003) action research cycle. A social validation interview was conducted following program completion to examine the athlete's responses to the emotion regulation intervention.

Results: Consultant's professional practice decisions and action taken to support the intervention are highlighted. Specifically, the employment and extension of Hanin's (2000c) IZOF profiling process to inform the development of athlete skills in emotion regulation are described. Moreover, how the content and intensity of performance related subjective emotion, physiological symptom, and cognitive zone profiles for optimal performance guided the identification and enhancement of techniques contributing to effective emotion regulation is illustrated. Athlete interview responses support the overall efficacy of the intervention program.

Conclusion: The present case study supports the efficacy of working within an IZOF framework from a consultant perspective. Furthermore, athlete reflections suggest enhanced skills in emotion regulation were perceived to result from the intervention.
\end{abstract}

(c) 2011 Elsevier Ltd. All rights reserved.
In sport, emotions have been defined as a subjectively experienced psychophysiological reaction to a real or imagined event (Vallerand \& Blanchard, 2000). Researchers acknowledge the central role of cognitions in generating such a subjective response (Jones, 2003). Indeed, Lazarus (2000) suggests cognitive appraisals of person-environment interactions and their relative importance to an individual's goals and well-being is key to the process of emotion generation and experience. Drawing from Lazarus (2000), Hanin (2007) considers emotion from a holistic perspective. In his view, emotions are a category of experience that reflects "a person's attitude toward different aspects of the environment and the meaning of the environment for the person" (Hanin, 2007, p. 32). As such, emotions are considered one of eight related components of an individual's psychobiosocial state of overall human functioning,

\footnotetext{
* Corresponding author. Tel.: +441214142873.

E-mail address: cjw787@bham.ac.uk (C. Woodcock).
}

and reflect on-going person-environment interactions informed by previous experience, a current situation, and expectations of future success (Hanin, 2010).

Emotions play a pivotal role in athletic performance (Hanin, 2000a; Robazza, 2006). In offering a comprehensive review, Jones (2003) identified motivational, physical, and cognitive mechanisms that mediate the relationship between emotions and performance. Emotions influence motivational processes by directing action tendencies toward (e.g., excitement) or away from (e.g., fear) a situation or stimuli (Vallerand \& Blanchard, 2000). Physical functioning is impacted by changes to physiological arousal that accompanies emotion. High levels of arousal have been seen to benefit performance on simple tasks that require power such as weight-lifting (Tod, Iredale, \& Gill, 2003), but can be detrimental to fine motor task performance (Noteboom, Fleshner, \& Enoka, 2001). Increases in arousal are also accompanied by a narrowing in attentional focus. Changes in attentional focus can benefit or harm performance depending on the task at hand and 
skill level of the athlete (Moran, 1996), and represent the main cognitive influence emotion has which holds implications for performance.

Viewed through an Individual Zone of Optimal Functioning (IZOF) lens, the emotion-performance relationship is explained by matching resources to task demands (Hanin, 2007). Specifically, emotions associated with optimal performance ensure efficient recruitment of resources in the mobilization of energy and utilization of skill for favorable task engagement (Hanin, 2000a). Conversely, emotions that are non-optimal reflect a demobilization of energy and miss-use of skill and are dysfunctional for performance (Hanin, 2000b). Given performance experiences are reflected in athletes' emotional states, several researchers have worked with athletes to control and optimize emotions for performance (e.g., Prapavessis \& Grove, 1991; Robazza, Pellizzari, \& Hanin, 2004).

As emotions are subjectively experienced, no one emotion is functionally beneficial for all athletes. Research supports the idiographic nature of how emotions impact performance (Hanin \& Syrjä, 1995). Thus there is a need in applied settings to examine emotion-performance relationships at an individual level. IZOF offers an individualized profiling procedure to identify the content and intensity of emotions for both optimal and non-optimal performances (Hanin, 2000c). These individualized patterns of emotions represent an athlete's optimal zone of functioning (optzone) as well as a dysfunctional zone (nonopt-zone).

According to the IZOF model, emotions form only one component of an athlete's psychobiosocial state (Hanin, 2000a, 2010). Seven other proposed dimensions are physiological symptom, cognition, motivation, performance, communication, behavior, and volition (Hanin, 2010). Stimulated by multi-dimensional conceptualizations of discrete emotions such as anxiety, physiological symptoms has arguably received the most attention in the literature to date. Following Hanin's (2000c) profiling procedure, support has been garnered for idiographic physiological symptom opt-zone and nonopt-zone patterns in relation to good and poor performances (Robazza \& Bortoli, 2003).

For subjective emotions and physiological symptoms, the IZOF model in/out zone-performance principle has received empirical support (Annesi, 1998; Robazza, Bortoli, \& Nougier, 2000; Robazza et al., 2004). This principle asserts the more proximal an athlete is to experiencing an opt-zone, the more likely superior performance will be achieved. In a similar vein, the probability of a poor performance increases when an athlete is close to a nonopt-zone. This emotion-performance relationship has been demonstrated for both subjective emotion (e.g., happy; Hanin \& Syrjä, 1995) and physiological zones (e.g., relaxed; Bortoli \& Robazza, 2002). When the experiences of these two forms of athletes' psychobiosocial state are considered together, they offer a stronger prediction for performance outcome in comparison to either emotions or physiological symptoms alone (Robazza et al., 2004).

More recently, Hanin (2007) distinguishes between state-like experiences, or emotional states, trait-like experiences, or stable emotional patterns, and meta-experiences. To date the majority of applied interventions has been concerned with athletes' state and trait-like experiences (Hanin, 2007). Robazza et al. (2004), for example, developed and delivered a 10 -week emotion regulation intervention for roller-hockey goal tenders and gymnasts to help these athletes approach subjective emotion and physiological optzone states immediately prior to performance. Following the intervention, athletes were able to approach opt-zone states and reported increases in subjective performance scores.

IZOF research has given less attention to meta-experiences (for an exception see Nieuwenhuys, Hanin, \& Bakker, 2008; Nieuwenhuys, Vos, Pijpstra, \& Bakker, 2011). Meta-experiences result from athletes' spontaneous reflection on conditions leading to good and poor performances that consequently contribute to knowledge and beliefs about an experience (Hanin, 2007). Thus meta-experiences influence athletes' choice of regulation techniques; the process and outcome of which is captured within a "triple-A" framework of awareness (of a psychobiosocial state), acceptance (of this state's functional impact), and action (employment of effective (or ineffective) coping strategies based on metaexperiences) (Hanin, 2007, 2010).

Triple-A offers a potentially helpful framework for describing the process of change during emotion regulation interventions (Nieuwenhuys et al., 2011). For example, when delivering an IZOF based intervention, awareness of opt-zone and nonopt-zone states is considered a necessary prerequisite to emotion regulation (Robazza et al., 2004). As a practical tool, Harmison (2006) suggests Hanin's (2000a) profiling process of zone identification enhances levels of awareness, and sets "the stage for...psychological skills and strategies to attain and maintain this mental and emotional state" (p. 240). Moreover, the profiling process allows athletes to identify, reflect, and accept the functional impact zone content has on performance (e.g., helpful or unhelpful). Drawing from the emotion regulation literature, and consistent with the IZOF in/out zone principle, awareness also extends to knowledge about ones current state (Fischer, Manstead, Evers, Timmers, \& Valk, 2004; Robazza et al., 2004). When a discrepancy exists between this state and one's optimal emotional experience, emotion regulation techniques may be employed to facilitate an opt-zone for performance. Such optimization of an emotional state may involve reduction (down-regulation), increase (up-regulation), and maintenance of optimal emotion intensity for task completion.

Previous IZOF intervention studies have helped athletes approach an opt-zone for performance (Annesi, 1998; Robazza et al., 2004). Although anecdotal reports made by previous consultants have supported working within an IZOF framework (e.g., Harmison, 2006), a systematic reflection of its benefits for an emotion regulation intervention has yet to be considered. Indeed, applied studies in sport psychology tend to center on intervention outcomes, and the framework guiding the process of intervention delivery is not often examined (Murphy, 2000). Thus the main aim of the present study is to explore the process of working with an athlete to facilitate skills of emotion regulation reflected in the processes of triple-A, current state awareness, and current statezone discrepancy detection (Fischer et al., 2004; Hanin, 2010).

To examine the process of applying practically based IZOF tools, a single case study methodology with a practitioner research approach was adopted. In so doing, the researcher, who often doubles as applied practitioner, is given a voice. Offering a firstperson consultant perspective has shown to be an elegant approach when describing the delivery of applied services in sport psychology (Andersen, 2000). Moreover, placing the consultant in the foreground helps answer the call for better documentation of practitioner practice (Simons \& Andersen, 1995).

The present investigation offers a single case study of the first author working with a university cross-country runner over a two month period. An action research approach was adopted to examine the 'how' of applied practice from the perspective of the consultant and athlete's response to an emotion regulation program. Action research has been proposed as an alternative approach to more traditional paradigms when examining interventions, and allows for close inspection of applied processes (Kellmann \& Beckmann, 2003). What distinguishes action research from reflective practice pieces is the involvement of strategic action (Evans, Fleming, \& Hardy, 2000). In sum, the present case study emphasizes procedural decisions and action taken to facilitate a female cross-country runner's skills in emotion regulation. 


\section{Method}

\section{Participants}

\section{First author and consultant}

A first-person action research approach was adopted to inquire about my own practice. "I" represents the voice of the first author and consultant. By undertaking this role, I was not an objective researcher looking in from a divorced position outside, but became a participant in the research process. To help contextualize the narrative, Huang (2010) suggests autobiographical information is necessary in anchoring "ownership of expression".

I was a competitive track and field athlete throughout school and university. During my final year of a BSc (Hons) Psychology degree, I was formally introduced to sport psychology. After completing an MSc in Performance Psychology, I began the British Association of Sport and Exercise Sciences (BASES) supervised experience for sport psychology scientific support. I have accumulated four years of supervised applied experiences, providing group and individual support to athletes varying in age, nationality, sport of engagement, and competitive level. At the time of the present study, I was in the second year of a Doctoral Program in Sport Psychology at a UK university.

My theoretical and philosophical approach has been informed by my postgraduate studies, and I view behavior change predominantly through a cognitive behavioral lens. Generally, cognitive behaviorists focus on intervention strategies but also acknowledge the importance of the consultant-athlete working alliance in meeting athletes' individual needs (Petitpas, Giges, \& Danish, 1999).

\section{Athlete client}

A female 19 year old cross-country runner contacted the university for sport psychology support. Anna (an alias) was in her first year of an undergraduate modern languages degree program. Anna was 3 months into her second season as a long-distance runner. At the point of contact, competitive experiences involved cross-country courses that ranged in distance from approximately $5 \mathrm{~km}-8 \mathrm{~km}$, as well as $1500 \mathrm{~m}, 3000 \mathrm{~m}, 5 \mathrm{~km}$, and $10 \mathrm{~km}$ road races. Personal best times for these specified distances were $5 \mathrm{~min} 08 \mathrm{~s}$, $11 \mathrm{~min} 18 \mathrm{~s}, 20 \mathrm{~min} 37 \mathrm{~s}$, and $45 \mathrm{~min} 30 \mathrm{~s}$, respectively. In her first season racing at a university level, Anna trained $4.5-6 \mathrm{~h}$ a week with the university's athletics club, and ran a further $2.5 \mathrm{~h}$ on her own or with fellow athletes each week. Anna reported no previous experience of psychological skills training.

\section{Situating action research}

Action research encompasses a family of approaches with no single definition or accepted protocol (Evans et al., 2000). This approach lends itself to a constructivist ontology and epistemology where assertions for an objective reality are rejected (Guba \& Lincoln, 1994). Instead, subjectively defined realities are constructed by individuals in an effort to impose meaning and order to the world (Krauss, 2005). Individual realities rest in the meaning afforded by cognitive processes rather than external objects or events themselves. In situating the current work within a constructivist paradigm, the present case study reflected a unique coming together of my own previous experiences, Anna's needs as an athlete, and the consultant-athlete relationship that was formed.

\section{Data collection}

\section{Reflective case notes}

Evans et al. (2000) note that in action research, "the researcher's...reflexivity often features prominently” (p. 301). As such, my own reflections played a central role in understanding the action research cycle and process of applied consultancy when working within an IZOF framework. The structure of my reflections followed Boud's (2001) reflective learning model and involved two levels of reflection: (a) to closely revisit the experience, and (b) re-evaluate the experience from an emotionally removed position. These two stages were prompted by asking and responding to the questions: (a) "What happened?" within $24 \mathrm{~h}$ of completing a consultancy session, and (b) "So what?" between 1 and 6 days afterward. This type of reflection has successfully been used previously to inform applied practice (Woodcock, Richards, \& Mugford, 2008), and allows a balance between my dual role as consultant and action researcher.

\section{Athlete interview}

Following the intervention, a semi-structured social validation interview was conducted. Martin and Hrycaiko (1983) recommend an interview guide that addresses athlete's perceptions of three main areas: (a) intervention goals, (b) procedures applied, and (c) results produced by these procedures. In-depth reflection of Anna's experience was facilitated by prompts (e.g., "what about the cue words you mentioned?") and probes (e.g., "why did you find imagery effective?") relating to each interview topic. Specifically elaboration probes were formed to encourage the athlete to provide an in-depth reflection of intervention experiences. To guard against social desirability and facilitate honest responses, the interview was conducted by a research associate not involved in the applied intervention who had previous experience interviewing athletes about sport psychology (Sharp, Woodcock, Holland, Duda, \& Cumming, 2010). The interview lasted for $38 \mathrm{~min}$ and was digitally audio-recorded and transcribed verbatim. A copy of the interview guide is available from the first author.

The interview transcript was subject to deductive content analysis to establish Anna's response to the emotion regulation program. The analysis process identified phrases that captured Anna's responses to the three social validation criteria (Martin \& Hrycaiko, 1983). Organized by these criteria, phrases that carried a similar meaning were grouped together (e.g., intervention goals, intervention procedures applied, and results produced). To establish trustworthiness of analytical results, Anna reviewed the interview transcript and interpretation of data responses (Lincoln \& Guba, 1985). She made no amendments to the data following this member check.

\section{Subjective performance}

A self-referenced performance rating was considered appropriate to measure performance outcome because differences between events in course length and terrain make it difficult for an objective measure to be obtained in cross-country running. Thus, Anna made a self-referenced performance assessment within 45 min of completing every cross-country event on an 11 point Likert scale $(1=$ worst performance to $11=$ best performance). Between the initial meeting and the first intervention session, Anna competed in four races. During the intervention, Anna competed in three races. The self-referenced ratings for each performance were plotted to allow for visual inspection of the case study data.

\section{Action research narrative}

The structure of the present narrative follows Kellmann and Beckmann's (2003) eight phase action research cycle (i.e., macrocycle) of: (a) joint problem identification, (b) consultation with a behavioral science expert, (c) data gathering and preliminary diagnosis, (d) supplying feedback to client, (e) joint diagnosis of issue, (f) joint action planning, (g) action, and (h) data gathering 
after action. At a macro-level, I systematically followed this action research cycle, however micro-cycles of action research also occurred during and between each applied session (see Fig. 1). These micro-cycles informed strategic action pursued in understanding and developing Anna's emotion regulation skills.

(a) Joint problem identification (athlete and coach)

Anna was struggling in her second cross-country running season to reproduce good training times in the competitive environment. Anna attributed this setback to weaknesses in the mental side of her performance, and recognized a need to manage debilitative emotions. Following coach recommendations, she contacted the school where the first author is based for psychological support.

\section{(b) Consultation with a behavioral science expert}

Following initial email correspondence, I met with Anna to discuss a potential working alliance. In return for psychological support, Anna agreed to take part in applied research that had been granted ethical approval by the school's ethics committee. As a research practitioner, I was aware of my own agenda and interest in exploring the efficacy of working within an IZOF framework. After explaining my research boundaries, Anna agreed to meet once a week for $1 \mathrm{~h}$ for the remaining two months of her cross-country season (for an overview of the 8-week intervention program see Table 1).

\section{(c) Data gathering and preliminary diagnosis}

The first step, when working within an IZOF framework, is to identify an athlete's opt-zone and nonopt-zone (Hanin, 2000c). This profiling process is supported by several worksheets. The aim of these worksheets is to bring an athlete's subjective experience of past events to the forefront. However, I was concerned an early introduction of paperwork may prove detrimental to developing consultant-client rapport (e.g., Beckmann \& Kellmann, 2003).

Instead, I first invited Anna to talk through her recent experiences as a runner (cf. Andersen, 2000). I gathered data (i.e., listened) and offered preliminary diagnoses (i.e., checking for understanding) by actively listening to Anna's personal account. Allowing Anna to tell her story helped her develop an awareness and acceptance of recent performance experiences. Further, my engagement with her tale demonstrated a desire to understand her needs and thus helped foster an effective working alliance (Andersen, 2000)
Listening to Anna tell her story, I heard a narrative of her performance experiences. An individual's self-narrative provides a framework for understanding life's events and is a process through which humans give meaning to an experience (Hanin, 2003). Within Anna's narrative, I heard clues to awareness (e.g., "I get distracted"), acceptance (e.g., "if I'm outside my comfort zone I freak out), and (ineffective regulatory) action (e.g., "my thoughts snowball out of control"). Examples of ineffective actions present potential barriers to optimal performance experiences (Giges, 2000), and highlight opportunities for enhancing skills in emotion regulation.

The IZOF model asserts the content of athletes' optimal emotional states depend on time (e.g., pre, during, post) and context (e.g., practice or competition). Accordingly, I was particularly interested when in Anna's sport participation ineffective action tended to occur. For Anna, these barriers to optimal performance appeared most prevalent during the beginning of her competitive races. Thus, during competition served as a potential time and context for the development of emotion regulation strategies.

I realized focusing on emotion patterns during a competitive event would mean a slight departure from the current IZOF evidence base. To date, IZOF work has focused on, and gathered predictive validity for, pre-competitive emotions (Hanin, 2000a; Prapavessis \& Grove, 1991). Entering a pre-competitive opt-zone for long duration tasks does not however guarantee on-going optzone proximity for a race's duration (Hanin, 2000a). Rather, feelings experienced during a long duration event explain a greater degree of performance variance (Jones, Mace, \& Williams, 2000).

These findings suggested to me two potential time points. First, focusing on pre-competitive zones would direct emotion regulation activities to promote an opt-zone immediately prior to a race (Robazza et al., 2004). Alternatively, we could concentrate on during event zones and develop regulatory skills at a time when performance barriers currently arose. Anna indicated a preference to focus on the latter. Anna did not perceive pre-race emotions to be an issue. Instead, Anna considered making a positive start by finding a good rhythm over the first kilometer of a race had a greater impact on her overall competitive experience.

Having agreed the time (i.e., during) and context (i.e., competition) on which to ground the emotion regulation program, I guided Anna through Hanin's (2000c) worksheets for the identification of zone content. First, Anna was asked to note down general features of her best and worst performances. A conscientious student, Anna articulated concerns about filling the forms in "correctly" with the "right" information. Listening to Anna's apprehensions, I recognized a potential for bias in Anna's written

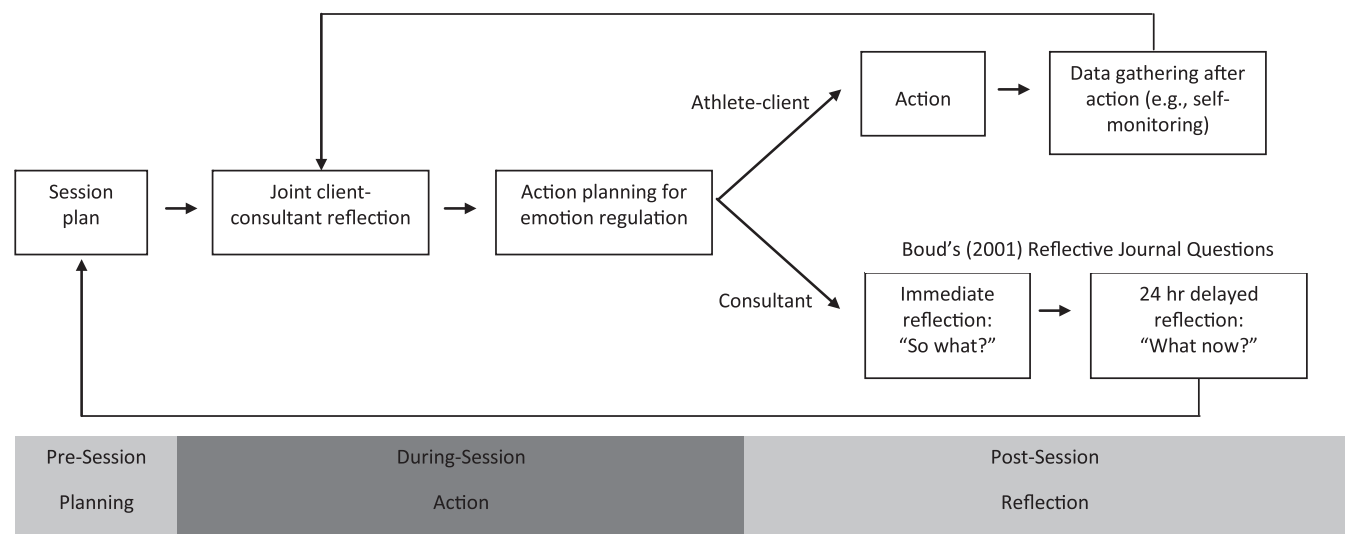

Fig. 1. Micro-cycle of action research occurring between each intervention session. 
Table 1

The themes, content, and purpose of Anna's emotion regulation program sessions.

\begin{tabular}{|c|c|c|c|}
\hline Session & Theme & Content $\&$ activities & Purpose \\
\hline 1 & Introductory session & a. Reflect on Anna's best and worst performance experiences. & $\begin{array}{l}\text { a. Increase Anna's awareness of her psychobiosocial performance } \\
\text { states, with particular emphasis on subjective emotions and } \\
\text { physiological symptoms. }\end{array}$ \\
\hline 2 & Zone identification & $\begin{array}{l}\text { a. Established the time (e.g., during the first } 1 \mathrm{~km} \text { of a race) } \\
\text { and context (e.g., competition) of zones to be identified. } \\
\text { b. Followed Hanin's (2000c) stepwise profiling process for } \\
\text { subjective emotions and physiological symptoms. }\end{array}$ & $\begin{array}{l}\text { a. Identify a salient phase of performance on which to focus the } \\
\text { emotion regulation intervention. } \\
\text { b. Identify opt-zone and nonopt-zone profiles during the first } \\
1 \mathrm{~km} \text { of a cross-country race and enhance meta-experience } \\
\text { of performance related subjective emotions and physiological } \\
\text { symptoms. }\end{array}$ \\
\hline 3 & Zone identification & a. Followed Hanin's (2000c) profiling process for cognitions. & $\begin{array}{l}\text { a. Identify opt-zone and nonopt-zone profiles during the first } \\
1 \mathrm{~km} \text { of a cross-country race and enhance meta-experience } \\
\text { of performance related cognitions. }\end{array}$ \\
\hline 4 & $\begin{array}{l}\text { Current emotion } \\
\text { regulation techniques }\end{array}$ & $\begin{array}{l}\text { a. Reflect on Anna's best (i.e., optimal) and worst } \\
\text { (i.e., non-optimal) performance experiences to identify any } \\
\text { emotion regulation techniques Anna currently uses. These } \\
\text { included goal setting and self-talk. }\end{array}$ & $\begin{array}{l}\text { a. Identify emotion regulation techniques Anna currently } \\
\text { employed, and accept the current effectiveness of these } \\
\text { techniques. }\end{array}$ \\
\hline 5 & Introduction to imagery & $\begin{array}{l}\text { a. Conduct introductory imagery activities adapted from } \\
\text { Vealey and Greenleaf (2006). }\end{array}$ & $\begin{array}{l}\text { a. Introduce Anna to, and build feelings of competence in, the } \\
\text { emotion regulation technique of imagery. }\end{array}$ \\
\hline 6 & Refining goal setting & $\begin{array}{l}\text { a. Reviewed Anna's imagery practice, and developed a } \\
\text { tailored imagery script incorporating opt-zone descriptor } \\
\text { words and phrases. }\end{array}$ & $\begin{array}{l}\text { a. To create a personally meaningful imagery script for Anna } \\
\text { to experience and reinforce her opt-zone performance states } \\
\text { in her mind. }\end{array}$ \\
\hline 7 & Refining self-talk & $\begin{array}{l}\text { b. Created a race plan for competitions (e.g., goal setting). } \\
\text { a. Reflected on Anna's practice of a tailored imagery script. } \\
\text { b. Review and refine current use of self-talk during races. }\end{array}$ & $\begin{array}{l}\text { b. Identify performance and process goals for competitive races. } \\
\text { a. To open a forum for discussion relating to Anna's imagery } \\
\text { experiences (e.g., helpful/unhelpful, clear and vivid). } \\
\text { b. To enhance Anna's awareness and acceptance of her } \\
\text { cognitive processes during a race. Identify functionally } \\
\text { beneficial cue words to aid achievement of process and } \\
\text { performance goals. }\end{array}$ \\
\hline 8 & $\begin{array}{l}\text { Review of the emotion } \\
\text { regulation program }\end{array}$ & $\begin{array}{l}\text { a. Reflect on athletes' experiences of the emotion } \\
\text { regulation program. }\end{array}$ & $\begin{array}{l}\text { a. Review what Anna found most helpful during the program, } \\
\text { and how she intended to continue to develop her skills in } \\
\text { emotion regulation following the intervention and cessation } \\
\text { of consultant support. }\end{array}$ \\
\hline
\end{tabular}

reflections that may have hindered her development of awareness. To prevent this problem, I suggested that she focus in on the highlights (and lowlights) that form her performance history as she had previously described, and reassured her there were no right or wrong answers.

For her best performance, Anna noted her familiarity with the cross-country course. This knowledge gave her confidence and enabled her to form a race plan. Motivated and determined to execute this plan, Anna described how she was able to concentrate on $1 \mathrm{~km}$ at a time. Anna did not perceive this race to be important, which helped her relax, and utilize her energy for running focused on her goals.

When Anna described her worst performance, a different experience emerged. Anna focused on a specific race in which she had considered her competitors to be better than her. Perceiving a difference in ability level, Anna began to doubt her own performance. She remembered as well an undulating course where it was difficult to find a regular rhythm. Unable to "get into her running" she recalled her muscles feeling tense and tired. Instead of being focused on the race, Anna's thoughts tended to center on task irrelevant stimuli during this performance.

Anna then identified what subjective emotions she experienced during the first kilometer of her favorable performances. To aid this process, Hanin (2000c) lists 96 emotion content descriptor words, grouped into positively (e.g., glad, active, calm, excited) and negatively (e.g., angry, afraid, doubtful, helpless) valenced terms. Consistent with zone identification procedures previously adopted (e.g., Robazza et al., 2004), I asked Anna to select up to five positive and five negative words that best captured her optimal feeling state. This process was repeated for Anna's poor performances. Anna identified 11 emotion content terms from a possible total of 20 descriptor words.

The next step in the profiling process determined the intensity each subjective emotion was experienced in being helpful or harmful for Anna's performance. Recalling previous performance states, Anna rated intensity levels on a modified version of Borg's CR-10 scale. Borg's (1998) numerical scale has verbal anchors placed at selected positions in such a way that it acquires ratio qualities. A frame of reference (from 0 to maximal possible) is provided that allows for inter- and intra-individual comparisons of intensity levels to be made, as well as guarding against ceiling effects. The CR-10 has thus been considered appropriate for assessing the intensity of emotional experiences (e.g., Hanin, 2000a; Hanin \& Syrjä, 1995; Robazza et al., 2004). Consistent with previous use of the CR-10 scale, the verbal anchors employed in the present study ranged from 0 (nothing at all) to 10 (very, very much) with a final option of 11 (maximal possible) to protect against ceiling effects. These ratings represented zone midpoints, and an arbitrary range of \pm 2 points was applied to obtain a zone range (Hanin, 2000b). A similar process was followed for identifying the content and intensity of physiological symptoms experienced during good and poor performances. It followed that four duringcompetition zones were identified for the beginning of Anna's races (e.g., an opt-zone and nonopt-zone, for subjective emotion content and associated physiological symptoms).

\section{(d) Supplying feedback to client}

A visual representation of each zone provided feedback to Anna of her subjective emotions (see Fig. 2) and physiological symptoms (see Fig. 3) relating to good and poor performances. The figures were constructed using Microsoft Excel and PowerPoint 2007. I guided Anna through each figure and highlighted areas that represented her opt-zone and nonopt-zone. Anna commented how better performances were characterized by positive emotions (e.g., confident, determined, and motivated), and contrasted with poor performances that were associated with negative emotions. A similar pattern of optimal-positive and non-optimal-negative 


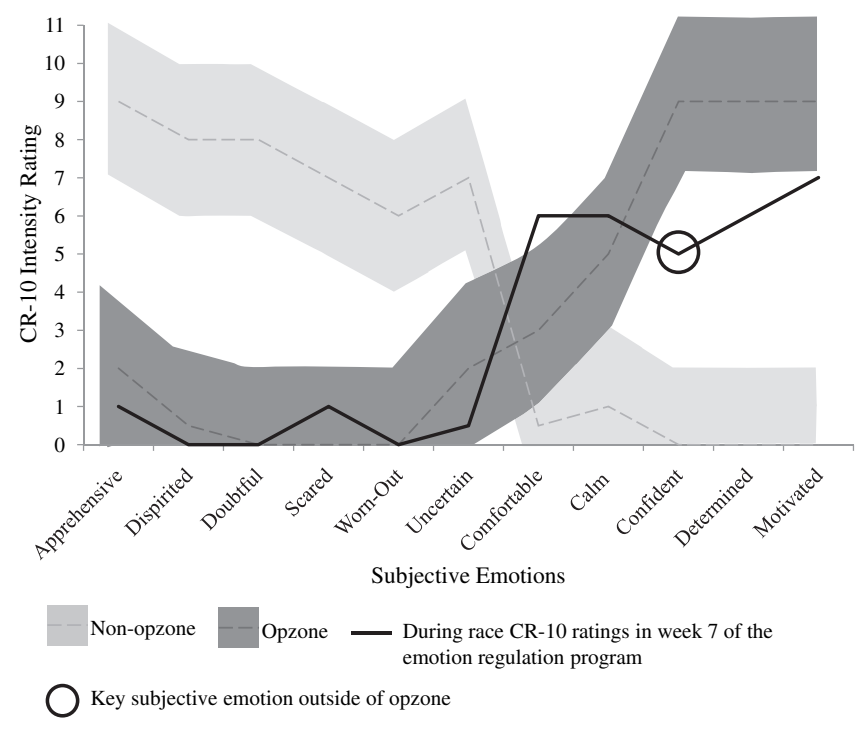

Fig. 2. Anna's emotion opzone and nonopzone during performance profile.

performance-emotion associations were viewed for physiological symptoms. Anna thought the figures helped to identify differences between her opt-zone and nonopt-zone emotion and physiological experiences.

I sensed the profiling process helped formalize Anna's performance experiences and contributed to her awareness and acceptance of emotions and physiological experiences during performance and related action. For example, during her worst performance, Anna vocalized an awareness of focusing on her competitors. She also articulated an acceptance that making such comparisons often led to debilitative thought processes such as thinking her competitors are superior to herself (cf. Nieuwenhuys et al., 2008).

\section{(e) Joint diagnosis of issue}

When regulating emotions, recommendations for the facilitation of desired emotional states have been made in favor of suppressing undesirable feelings (Uphill, McCarthy, \& Jones, 2009). Thus, focusing on the facilitation of opt-zone experiences, rather

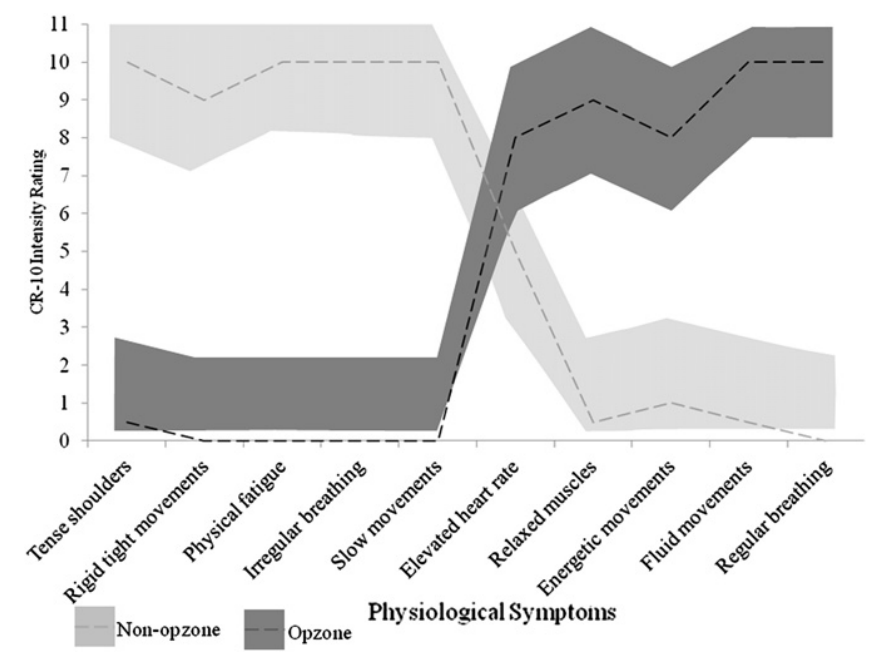

Fig. 3. Anna's physiological symptom opzone and nonopzone during performance profile. than the suppression of nonopt-zone states, I asked Anna which she considered most important. Anna identified key subjective emotions and physiological symptoms for facilitation by inspecting Figs. 2 and 3 for large discrepancies between opt-zone and nonoptzone intensity ratings. Specifically, Anna indicated confidence, determination, and motivation coupled with relaxed muscles, fluid, energetic movements and a regular breathing rhythm to be most desirable for performance and these were prioritized for regulation.

Adding a cognitive piece to the puzzle

The role of cognitions is central to emotion generation (e.g., Lazarus, 2000), response (Jones, 2003), and regulation (Gross \& Thompson, 2007). Furthermore, cognitions are viewed as a component of Hanin's (2000a) psychobiosocial state. Although Anna identified key subjective and physiological responses for performance, I considered these to be tied to underlying cognitive processes that deserved further exploration. I felt increasing Anna's awareness of her thought processes and the impact they had on performance was essential in furthering her (and my) understanding of her overall emotional experiences during competition.

The IZOF profiling procedure has been recommended for the cognitive modality (Hanin, 2000c). Indeed, cognitive descriptors have spontaneously emerged in previous profiling exercises (Hanin \& Stambulova, 2002), and omission of this modality has been viewed as a potential weakness in the applied domain (Robazza et al., 2004). A review of the literature failed to highlight previous work in affect-related cognitive zones, and a descriptor list for zone identification was not available. As Anna's performance reflections were rich with cognitive references, I nevertheless felt it worthwhile to pursue zone identification for cognitions.

In the absence of a cognition descriptor list, I returned to the narrative method of identifying idiosyncratic content of performance experiences (Hanin, 2003). To aid this process, I posed questions to Anna concerning her affect-related cognitions during previous sport experiences (e.g., "what thoughts passed through your mind when you feel confident during a race?"). Anna initially had difficulty in identifying thoughts associated with better performances. Following further inquiry through guided reflections of previous performances, Anna realized she used self-instructions such as "catch the person in front", and reported an overall feeling of certainty. Otherwise, Anna commented she "didn't really think of anything", suggesting a state of automaticity and a cognitive state reminiscent of the flow experience (Jackson, 2000).

In contrast, cognitions associated with poor performances came easier to Anna. Self-statements, such as "I'm unfit" or "everyone's better than me", tended to build into worrisome rumination during races. After reflecting on these destructive thoughts, Anna expressed a desire for them to stop. Anna accepted the debilitative function of these cognitions and saw no point running when "in this mental state".

To identify her cognitive opt-zone and nonopt-zone, Anna rated the extent to which she experienced these thoughts during the start of a good and poor race on the CR-10 scale. Visual representations of Anna's affect-related cognitive opt-zone and nonoptzone were created and provided further feedback to facilitate Anna's awareness and acceptance of her thought patterns during her best and worst performances (see Fig. 4).

\section{(f) Joint action planning}

Up to this point, Anna had developed awareness (i.e., what she feels emotionally and physically, and thinks cognitively), acceptance (i.e., the functional impact these feelings and thoughts have on performance), and associated action (i.e., regulatory strategies) across three related modalities for performance. When ineffective 


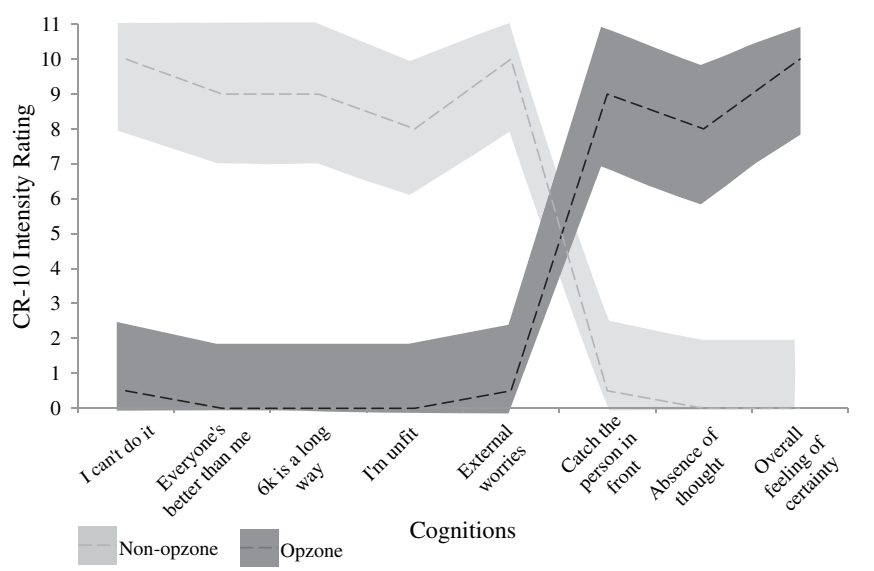

Fig. 4. Anna's cognitive opzone and nonopzone during performance profile.

action is adopted (e.g., de-motivating self-talk), more effective regulatory action is required. For this to occur, Fischer et al. (2004) point to the importance of athletes developing a present-moment awareness of current emotion states, and an ability to recognize when discrepancies arise between this and a desired state (i.e., optzone).

Subsequent joint consultations were therefore planned to realize these objectives and involved three aims: (1) to build on the IZOF profiling work in maintaining Anna's opt-zone meta-experience across all three modalities, (2) to foster Anna's awareness and acceptance of her current performance state, and (3) to assist effective action in identifying, refining, and employing regulatory strategies for opt-zone nonopt-zone discrepancy reduction with respect to all three modalities.

\section{(g) Action}

\section{Maintaining opt-zone meta-experience}

Anna was encouraged to reflect on her IZOF profiles to maintain awareness and acceptance of her subjective emotion, physiological, and cognitive opt-zones (see Figs. 2-4). To further facilitate optzone awareness, acceptance, and action, I asked Anna if she was willing to try imagery in the fifth week of the intervention. Imagery has been recommended as an effective technique for facilitating awareness (Hanin \& Hanina, 2009; Ravizza, 2006), and would allow Anna to recreate optimal affective experiences in her mind. I first guided Anna through a basic imagery exercise to familiarize her with the technique. These exercises, adapted from Vealey and Greenleaf (2006), introduced Anna to imagery attributes of vividness and controllability through imaging familiar training and competition environments.

Following these exercises, I developed an imagery script that contained characteristics of Anna's ideal performance state. Drawing from Lang's (1979) bio-informational theory of emotional imagery, the script was formed of stimulus, response, and meaning propositions. To ensure the imagery was familiar and meaningful to Anna, these propositions drew from components of her opt-zone profiles. Imagery scripts comprising all three proposition types maximize emotional arousal and imagery vividness (Lang, Kozak, Miller, Levin, \& McLean, 1980), and thus were used to facilitate Anna's awareness of her desired state for performance.

Anna's script asked her to imagine herself at the start of a race and guided her through the first kilometer. Cognitive meaning propositions included adaptive appraisals of this stimulus event. Associated with these cognitive processes were optimal subjective, physiological, and cognitive responses. Excerpts from Anna's script illustrating this stimulus, response, and meaning propositions include: "confidence grows as you focus on catching the person in front" as well as "your mind is on your race...your breathing is steady". Guided by this script, Anna imaged five times a week for the remaining three weeks of the emotion regulation program. Further, in a competition week, Anna would image herself running in the upcoming race to reinforce opt-zone thoughts and feeling states in preparation for the event.

\section{Awareness of current performance state}

Self-monitoring techniques are recommended to enhance awareness (Ravizza, 2006). Thus, individualized self-monitoring tools were employed to facilitate Anna's awareness of her current performance state during the first kilometer of a race. Three idiographic lists generated from Hanin's (2000c) profiling process were employed. Each list contained Anna's subjective emotions, physiological symptoms, and associated cognitions for performance. Using the CR-10 scale, Anna rated the intensity she experienced each component during the first part of a race. This self-monitoring was conducted within 45 min of race completion to help develop awareness for her current performance state.

Monitoring sheets also informed joint client-consultant reflections. Specifically, intensity ratings were plotted on the same axis as Anna's opt-zone and nonopt-zone to highlight zone proximity and indicated discrepancies between current and desired emotional states (see Fig. 2 for an example). Joint consideration was given to her specific ratings to further my own as well as Anna's understanding of her emotional experiences. For example, if Anna rated her intensity of confidence experienced as five out of a potential 11 on the CR-10 scale, I would ask why she felt it was at this level. Such questions were designed to help Anna understand discrepancies experienced from her opt-zone and inform consequent regulatory efforts.

\section{Refining current emotion regulation strategies}

Experienced athletes often implicitly employ techniques (e.g., imagery) for emotion regulation. Consultants help athletes to recognize and develop these naturally learned techniques to become systematic regulatory strategies (e.g., Robazza et al., 2004). I was thus interested in Anna's current mental techniques implicitly employed for regulating her emotions in forming a foundation for strategy development.

Only in her second cross-country season, Anna was not an experienced runner. However, when reflecting on previous performances, her use of several emotion regulation strategies became apparent. During superior performances, Anna employed goal setting and self-talk strategies. Optimal emotion responses occurred when she had specific performance goals set for competition. These goals appeared to foster an appropriate attentional focus and were coupled with positive thoughts. Conversely, nonoptimal emotions transpired when Anna was unfamiliar with a course and was not ready for the undulations and terrain. Feeling ill-prepared, Anna lacked focus and became distracted by task irrelevant thoughts such as worrying about her competitors. Consequently, we focused on developing and refining Anna's current regulatory strategies of effective planning and goal setting for appropriate attention deployment and adaptive appraisal of stimuli through positive self-talk.

The setting of process and performance goals as a technique for attentional deployment has gained support in the literature. Kingston and Hardy (1997) found process goals that focus on an athlete's desired behaviors and actions to facilitate appropriate focus of attention. The setting of performance goals (e.g., to run a specific time) has received support for fostering confidence (Filby, Maynard, \& Graydon, 1999), and feelings of motivation and 
determination (Burton \& Weiss, 2008). Thus, we would expect Anna's use of performance and process goals to facilitate appropriate attentional deployment and promote optimal subjective emotion experiences she had identified as key for performance.

Anna's current goal setting strategies involved vague "do your best" goals set by her coach. Drawing from the SMART acronym (Specific, Measurable, Adjustable, Realistic, Time-bound), I discussed the principles of effective goal setting with Anna. Incorporating these principles, Anna identified performance goals that she had ownership over. First, Anna considered specific race times that she perceived challenging yet achievable. For cross-country courses she had previously experienced, performance goals were based on times recorded for the same course and terrain. For unfamiliar cross-country courses, Anna agreed to consult runners who knew the course to inform the setting of a more flexible performance goal (e.g., a range of potential race times). Reducing the specificity of the performance goal to a time range was considered favorable over Anna returning to her very general and non-specific "do your best" goals. Second, Anna identified process goals that were enlightened by her physiological opt-zone. Indeed, for the first kilometer of a race, Anna's process goal or target was to find a good rhythm by focusing on regular breathing. Process goals that reflect rhythm were favored over more specific technical aims, such as the mechanics of Anna's running gait, so automaticity of the movement was not interrupted (Kingston \& Hardy, 1997).

A second regulatory technique that Anna implicitly used was self-talk. Research supports athletes' internal dialog as directing focus of attention as well as affecting feelings of confidence and motivation (Zinsser, Bunker, \& Williams, 2006). Thus, we worked together to refine Anna's self-talk to facilitate these key characteristics of her opt-zone.

Anna developed awareness of helpful and unhelpful self-talk when identifying her cognitive zone. During this process, Anna identified the content of self-talk statements. For example, phrases associated with her nonopt-zone involved a number of debilitating appraisals (e.g., "6 km is a long way"), and self-defeatist reinforcements (e.g., "I'm so unfit"). Whereas self-talk during optimal performances, included motivational instructions such as "just run" and "catch the person in front". Previous research suggests increasing awareness of self-talk is not enough to initiate motivation for change (Hardy, Roberts, \& Hardy, 2009). Identifying selftalk statements in relation to good and poor performances however helped Anna to increase her awareness of self-talk use, as well as its functional impact (e.g., helpful or unhelpful). In line with Hanin's $(2007,2010)$ triple-A framework, enhancing awareness and acceptance were currently viewed as a necessary precursor for change and subsequent self regulatory efforts.

Previous research has cautioned against the use of thought suppressing techniques such as thought stoppage (Hardy et al., 2009). Instead of consciously suppressing unhelpful thoughts, Anna was simply encouraged to focus on helpful thoughts. A time for Anna to draw upon helpful cue words was identified to facilitate effective use of these self-talk statements. For example, Anna considered using the cue word "focus" during the first kilometer of her race to help attain her process goal.

\section{Effective regulation toward an opt-zone}

Anna practiced goal setting and self-talk to foster opt-zone subjective, physiological, and cognitive experiences for the first kilometer of her race. Inconsistencies between her current and optzone states for each modality functioned as a signal for the employment of these strategies. To further develop her ability to recognize and reduce any discrepancy, we extended Anna's original imagery script. Specifically, features of her process goals (e.g., focus on her rhythm) and self-talk (e.g., just run) were incorporated as response propositions to reinforce strategy employment for optzone promotion.

\section{(h) Data gathering after action (social validation interview)}

The action research cycle has thus far detailed consultant professional practice decisions and action taken to facilitate a female cross-country runner's skills in emotion regulation when working within an IZOF framework. Following the intervention it is however important to gauge what has changed for the athlete. A formal social validation interview was conducted that gathered Anna's responses to intervention goals, the procedures applied, and subsequent results produced (Martin \& Hrycaiko, 1983).

\section{Intervention goals}

Anna agreed that grounding the intervention on her affective experiences during the first kilometer of a race was the right focus. For Anna, the need to foster mental strength during a race was pivotal to prevent "all the negative thoughts". Anna explained this was "because I'd generally...start feeling positive for three seconds... and then just lose [myself] completely". Pre-intervention, Anna recognized that she used to "start quite positively and quite strongly and then sort of dwindle". Thus, it was deemed that having the ability to build on a positive start by employing during race strategies was an important skill for Anna to develop.

\section{Intervention procedures applied}

When considering the intervention sessions, Anna noted being able to "talk about [and] reflect on races" was beneficial. Coming from a small running club, Anna felt "a little bit insignificant" in the university running environment. Anna thought "it was nice to have [the consultant]" who she found to be "very approachable". Anna reflected how she "could quite comfortably come in and just be like 'I had an awful race' and not think twice about [disclosing]".

Anna also found the IZOF profiling process helpful. In particular, having a visual representation of affect-related performance states facilitated awareness of functionally optimal emotions across events. Anna noted that "feelings associated with...running well, like on the graph, there was a similar pattern...when [she was subsequently] running well".

Reflecting on her emotion regulation strategies, Anna reported practicing imagery the most often and noted "I didn't find it a problem having to sit down and listen to them [scripts] and try and picture them [races]". Anna described imagery as "easy, it was a new idea I'd never done before but it wasn't a strange one". However, imaging new circumstances was a challenge for Anna as she said "I found it harder to image things that hadn't happened before". Consequently, Anna's planning and goal setting were used to develop individualized scripts to help facilitate her ability to image future race performances. Specifically, Anna perceived how "[the consultant] did a script to match my plan which was good because I could sit in my room and pretend I was running the race and how I'd feel".

In contrast, Anna used her self-talk cue words the least often, as this technique was introduced in the penultimate session of the intervention. At the time of the interview, Anna felt she had not fully integrated this regulatory technique into her self-regulation repertoire. This point is illustrated by Anna saying, "I've got a race coming up that I was going to try and use them for". Although Anna had used her cue words during training to help her attentional focus, as she describes, "I tend to not focus... we'd be on the last set of a rep and I'll feel like I can't do it and then I would be just like 'focus on the person in front if you stay with them you'll get through". 
Although Anna did not find goal setting "a difficult concept to grasp", she reported difficulties when setting targets. She noted how "sometimes [I] found it hard to think of realistic targets...I'd always expect too much of myself". However, over the course of the sessions Anna described how she was able to break her race down into components and use cue words to focus her mind on realistic aims. For example, Anna reflected how she set targets for separate phases of a race: "I'd set my target for the first phase [race time]... and the second phase [find rhythm]...my target phrase was 'just run' so that [kept] me moving forward, and then the third phase was to finish strong".

\section{Results produced}

The results produced center on three main intervention outcomes: (a) Anna's emotional state, associated physiological symptoms, and cognitions, (b) Anna's perceived changes to the performance process, and (c) performance outcome. Before seeking psychological support, Anna found races "awful...I used to find it really hard to just get a grip on the reality of it all. I'd always blow it out of proportion in my head". Following the emotion regulation program, Anna reported being "a lot more in control of where I feel at races". Anna viewed the process of setting goals as having helped her gain perspective and decrease the intensity of nonopt-zone emotions such as feelings of uncertainty. For example, she noted "when I'm bit unsure of myself or if I think it's a seemingly impossible task I'd be like right let's start with 'stay with your friend' or 'running this time' and then see from there". Anna also reported how imaging upcoming races helped prepare her for the event. She no longer felt like she was stepping into the unknown.

In relation to her physiological symptoms, Anna considered "I have definitely started to relax a bit more at competition and started to enjoy them". Anna's perceptions of competitive races also changed post-intervention. This impact on cognitions is illustrated by Anna as she describes how “I wouldn't freak out completely...I'd start to think more positively at the start of the race...set myself goals and not to worry so much". In sum, Anna felt "just generally more in control of everything...I felt like I was running the race for me and not...just being slung in the deep end and told to run".

When considering the process of performance, Anna perceived the emotion regulation strategies to be effective for fostering desirable opt-zone psychological qualities. During races, when Anna found it difficult to concentrate, she would "try and use the techniques to help my racing at each stage". Specifically, Anna noted how goal setting facilitated opt-zone descriptors of motivation and determination: "[goal setting] definitely helped me focus a lot more, and to push myself a lot more...setting targets is more motivating to achieve them and they're realistic...whereas before they'd be unrealistic and I'd just not try". Anna noted how she also employed self-talk to keep her goals in mind during performance. For example, she said "when I start to lose focus [and] concentration in a race, I just think of the cue word which reminds me of the target I set for that particular stage". Thus, self-talk helped Anna commit to her process goals by maintaining an appropriate focus of attention on task relevant stimuli.

Anna also employed emotion regulation techniques during training runs. In particular, the employment of imagery was described in relation to opt-zone descriptors of motivation and determination: "if I [felt] I couldn't finish the session I'd use to picture myself finishing the session, and that made it easier to do". Furthermore, Anna set goals to help minimize feelings of doubt "before a training session...I was a bit worried about being able to finish the session so I made a point of finishing the session with everyone".

Anna's self-referenced ratings of performance offer further insight into the impact of the emotion regulation program on performance outcome. Visual inspection of Fig. 5 suggests Anna's perceptions of performance outcome during the intervention had less variability than pre-intervention. For the four races Anna competed in pre-intervention, subjective ratings ranged from 3 to 9 $(M=5.25, S D=2.63)$. During the intervention, Anna's subjective performance ratings decreased in variability. That is, for the three competitive races completed during the intervention, Anna rated her performances between 6 and $9(M=7.33, S D=1.53)$. Further, Anna's mean subjective performance score increased from pre to during the intervention.

\section{Final reflections}

The present study adopted an action research approach to help address a recognized need within sport psychology for well documented intervention studies (Kellmann \& Beckmann, 2003). The process of working within Hanin's (2000a) IZOF framework to promote a university level cross-country runner's emotion regulation skills was examined in a single case study. Following Kellmann and Beckmann's (2003) action research cycle, procedural decisions and action taken during a two month intervention were highlighted. In developing meta-experiences of awareness and acceptance, the athlete reported use of regulation techniques to enhance the likelihood of experiencing optimal states for performance. Indeed, Hanin's (2000c) individualized profiling process lent itself well to developing pre-requisites to emotion regulation of enhancing athlete awareness of a desired affect-related performance state, as well as having the ability to detect discrepancies with current emotional experiences (Fischer et al., 2004). Moreover, the content and intensity of emotion responses in the athlete's optimal (opt-zone) and non-optimal (nonopt-zone) zones of functioning guided the development of emotion regulation strategies.

The present study was novel in describing an IZOF based intervention that focused on during event zones of functioning. The majority of previous research has examined components of precompetitive psychobiosocial states (e.g., Robazza et al., 2004). Difficulties in measuring zone proximity during events have been highlighted, and explain why research in this area has received limited attention (Hanin, 2000a). The present study relied on the athlete's immediate reflection on performance experiences following a race. In the current "real world" setting, such a dependence on athlete recall was not viewed as a limitation. Indeed, consultant reflections suggest encouraging athlete systematic selfreflection served to enhance meta-experiences of awareness (i.e., knowledge of performance related states), and acceptance (i.e., functional impact) processes related to action outcomes.

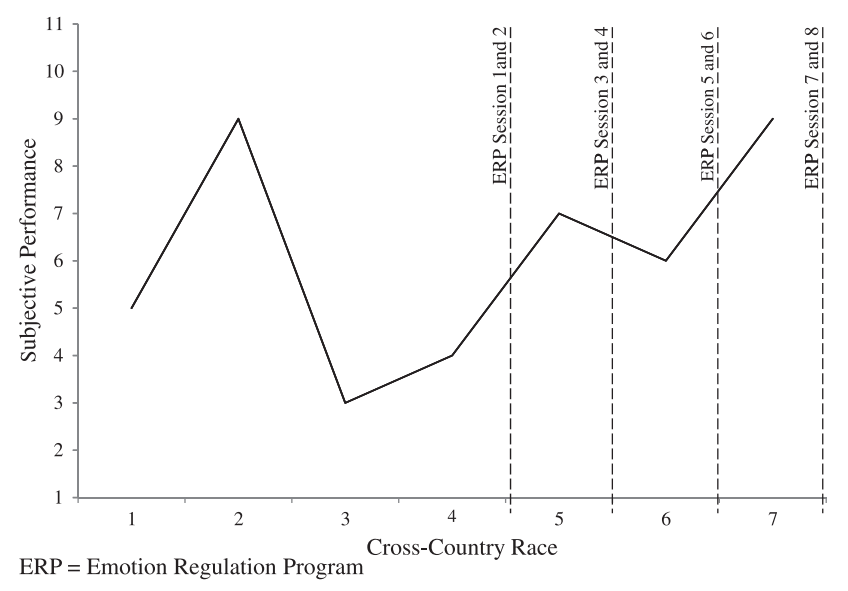

Fig. 5. Anna's subjective performance ratings. 
Only focusing on the first kilometer of a cross-country race, the study did not examine the dynamics of emotional experiences for the event's duration (cf. Nieuwenhuys et al., 2008, 2011). In the social validation interview, it is therefore interesting to note the athlete reported breaking the race down into several phases. Viewing a cross-country event in multiple sub-components is reminiscent of Anna's original reflections on best performance where she reported running $1 \mathrm{~km}$ at a time. This process of task compartmentalization suggests how a chain of movement can be created for events such as cross-country running. This is reflective of Hanin and Hanina's (2009) action-centered profiling. Athletes describe a component chain of subjective experiences of task execution to describe a performance event. This form of profiling can capture the dynamics of long duration events and thus offers a promising avenue for future research and application.

In line with previous research, consultant reflections suggest the process of zone identification facilitated athlete awareness and acceptance of desired emotional states (Harmison, 2006). However, these meta-experiences were further developed through the deliberate and systematic practice of imagery. Previously, imagery has also been used to enhance recall of motor tasks as a means of increasing conceptual and physical awareness (Hanin \& Hanina, 2009). The athlete participating in this case study was able to re-experience multiple opt-zone characteristics in her mind that reinforced favorable feelings associated with optimal performance.

The enhanced levels of athlete awareness of current and desired emotion states and athlete acceptance of functional impact were further maintained through self-monitoring. Plotting current intensity ratings of emotion descriptors against zone ratings in figure form illustrates current-desired state discrepancies and highlights on-going regulatory needs to inform intervention strategies. Moreover, using monitoring tools for the on-going assessment of zone proximity provides a potential measure of emotion regulation skills and intervention effectiveness.

Although Hanin's (2000c) profiling process offered pragmatic tools for guiding applied practice, the process of delivery was considered central to intervention effectiveness. At the start of the program, the consultant recognized the importance of developing rapport with the athlete before zone identification (Petitpas et al., 1999). To help meet this aim, the athlete was encouraged to reflect on performances in her own words (Andersen, 2000). Similarly, previous IZOF research has noted how an athlete "was happy that somebody actually listened to his story for once" (Nieuwenhuys et al., 2008, p. 70). Allowing athletes to form selfnarratives also helps give meaning to performance experiences (Hanin, 2003). Taking these previous observations together with present consultant reflections, the delivery of applied programs utilizing Hanin's (2000c) profiling process should emphasize development of client-consultant rapport through the use of active listening skills. Such a positive working alliance can be developed by helping athletes tell their stories, and construct a self-narrative of performance experiences.

Previously, Hanin (2000b) has recommended the profiling process to be used predominantly with experienced athletes who are assumed to have a necessary level of awareness for zone identification. Inexperienced athletes, who do not have an extensive performance history, have difficulties identifying valid zones (Hanin \& Syrjä, 1995). However, the present study demonstrated that an inexperienced athlete who was in her second competitive season was able to identify meaningful zones that informed the development and delivery of an effective emotion regulation program. Consultant and athlete reflections suggest Anna's participation in the IZOF based intervention influenced her metaexperiences associated with emotions, physiological symptoms, and cognitions for performance. Although the validity of zones in the present case was not established, findings suggest that the application of IZOF processes can form a beneficial foundation to interventions with less experienced athletes.

Although the present study suggests the IZOF model is appropriate for enhancing inexperienced athletes' meta-experience of emotional states and their regulation, some caution is warranted. The IZOF model specifies four global categories of emotions based on valence and functionality (Hanin, 2000a, 2000b). These categories include pleasant-helpful ( $\mathrm{P}+$; e.g., determined), unpleasanthelpful ( $\mathrm{N}+$; e.g., anxious), pleasant-unhelpful (P-; e.g., selfassured), and unpleasant-unhelpful (N-; e.g., fearful) emotional states. In the current single case study, the athlete's emotion profile only contained two of these categories; namely, $\mathrm{P}+$ and $\mathrm{N}-$. This is in contrast to previous research with more experienced athletes where all four categories are represented (Hanin \& Syrjä, 1995; Robazza \& Bortoli, 2003; Robazza et al., 2004). The present finding highlights a potential qualitative and quantitative difference between non-elite and elite athletes' zone profiles.

Research in anxiety may help to explicate why hedonic-function reversal effects were not observed in the present study. Elite athletes tend to report anxiety (cognitive and somatic) to be facilitative (e.g., $\mathrm{N}+$ ), whereas non-elite athletes perceive this emotion to be debilitative (e.g., N-; Jones, Hanton, \& Swain, 1994). Individual differences and perceptions of control are proposed as potential mechanisms mediating interpretation of anxiety direction (Jones, 1995). Further research should examine whether perceived reversals in function in a wide array of pleasant and unpleasant emotions (e.g., P-, $\mathrm{N}+$ ) can also be explained by similar mechanisms (for a review see Mellalieu, Hanton, \& Fletcher, 2006).

The present case study described key regulation techniques developed such as imagery, goal setting, and self-talk (e.g., Annesi, 1998; Prapavessis \& Grove, 1991; Robazza et al., 2004). Individualization of techniques, by incorporating information from athlete zone profiles, has not been considered until now. Opt-zone descriptor words were particularly salient for creating an imagery script that contained stimulus, meaning, and response propositions relevant to the athlete. Individualization of scripts was found important for imaging new experiences, such as desired performance states for upcoming races. Furthermore, previous research suggests such individualization of techniques promotes overall intervention effectiveness (Bull, 1991).

Consistent with previous work, the potential for identifying cognitive zones within the implementation of emotion regulation interventions has been highlighted in the present work (Hanin \& Stambulova, 2002; Robazza et al., 2004). A novel feature of this case study was the extension of Hanin's (2000c) profiling process to identify a cognitive zone. An athlete-generated idiographic representation of affect-related thought processes offers insight into the individual meaning given to person-environment interactions and associated emotions (Lazarus, 2000). This strategic action facilitated athlete awareness of attention, appraisal processes, and cognitive responses, and developed an individualized selfmonitoring tool for affect-related cognitions for performance.

Further research is warranted to examine the cognitive modality of affect-related performance states. The present athlete's cognitive profile consisted of both self-statements (e.g., "6 km is a long way") and broader cognitions (e.g., external worries). Adopting an applied perspective, the former seems to facilitate awareness of appraisal content and the impact of self-talk on emotions. However, viewing cognitions through an IZOF theoretical lens, the latter may prove insightful when examining relationships with subjective and physiologically-based emotional responses. Further, a promising tool for assessing multiple components of athletes' psychobiosocial state has recently been developed, and may prove to be useful 
in profiling individualized multimodal states (Ruiz, Hanin, \& Robazza, 2011).

The focus of the present study was on the 'how' of applied practice. Nevertheless, one of the important principles in the IZOF model is the assumed zone-performance relationship. Compared to pre-intervention ratings, observed subjective performance scores suggested that the athlete was able to perform more consistently during the intervention. This finding was further reflected in the athlete's post-intervention interview in which enhanced perceptions of control, motivation, and appropriate focus of attention were reported. The current results related to subjective performance ratings should, however, be viewed with caution. A relatively small number of performances were obtained, and only three races were completed during the intervention phase. Further, two intervention sessions were delivered after all performance data had been obtained. Therefore, the obtained subjective performance scores do not reflect the whole 8-week intervention.

A main limitation of the present case study was that the narrative was predominantly informed by consultant reflections. Future research should conduct more comprehensive evaluation on emotion regulation program effectiveness from an athlete's perspective. Alternative methods of data collection such as multiple interviews, or diary studies, would capture processes of change across an IZOF based intervention, including early changes that athletes may fail to report in a social validation interview. Future research may also find Nieuwenhuys et al. $(2008,2011)$ effective use of Miles and Huberman's (1994) composite sequence analysis for such in-depth dynamic investigations as a useful point of reference. For measuring performance, goal attainment scaling may also offer an alternative quantitative measure to ascertain whether change pre to post-intervention may be deemed meaningful by the athlete (Kiresuk \& Sherman, 1968; Mellalieu, Hanton, \& O'Brien, 2006).

To summarize, the present case study offers a first-person account of applied practice working within an IZOF framework for the purpose of enhancing athlete skills in emotion regulation. The in-depth examination detailed the 'how' of the IZOF profiling process, and its use to enhance athletes' meta-experiences, as well as the selection and individualization of effective regulatory strategies. It would be interesting for subsequent research to consider the extension of the IZOF model to a cognitive modality in order to develop an evidence base to inform future applied practice.

\section{Role of the funding source}

The funding source contributed to a Ph.D. studentship for the first author. The funding body did not contribute to study design, data collection, data analysis, or the interpretation of findings.

\section{Acknowledgments}

The authors would like to thank the Winning Scotland Foundation whose funds made the present study possible.

\section{References}

Andersen, M. B. (2000). Beginnings: intakes and the initiation of relationships. In M. B. Andersen (Ed.), Doing sport psychology (pp. 3-16). Leeds, UK: Human Kinetics.

Annesi, J. J. (1998). Applications of the Individual Zones of Optimal Functioning model for the multimodal treatment of precompetitive anxiety. The Sport Psychologist, 12, 300-316.

Beckmann, J., \& Kellmann, M. (2003). Procedures and principles of sport psychological assessment. The Sport Psychologist, 17, 338-350.

Borg, G. (1998). Borg's perceived exertion and pain scales. Leeds, UK: Human Kinetics.
Bortoli, L., \& Robazza, C. (2002). Idiosyncratic performance affect in volleyball referees: an extension of the IZOF-emotion model profiling. Journal of Sport Behavior, 25, 115-133.

Boud, D. (2001). Using journal writing to enhance reflective practice. In L. A. English, \& M. A. Gillen (Eds.), Promoting journal writing in adult education, Vol. 90 (pp. 9-18). San Francisco, CA: Jossey-Bass.

Bull, S. J. (1991). Personal and situational influences on adherence to mental skills training. Journal of Sport \& Exercise Psychology, 13, 121-132.

Burton, D., \& Weiss, C. (2008). The fundamental goal concept: the path to process and performance success. In T. S. Horn (Ed.), Advances in sport psychology (pp. 339-375). Champaign, Il: Human Kinetics.

Evans, L., Fleming, S., \& Hardy, L. (2000). Situating action research: a response to Gilbourne. The Sport Psychologist, 14, 206-303.

Filby, W. C. D., Maynard, I. W., \& Graydon, J. K. (1999). The effect of multiple-goal strategies on performance outcomes in training and competition. Journal of Applied Sport Psychology, 11, 230-246. doi:10.1080/10413209908404202.

Fischer, A., Manstead, A. S. R., Evers, C., Timmers, M., \& Valk, G. (2004). Motives and norms underlying emotion regulation. In P. Philippot, \& R. S. Feldman (Eds.), The regulation of emotion (pp. 189-214). London, UK: Lawrence Erlbaum Associates.

Giges, B. (2000). Removing psychological barriers: clearing the way. In M. B. Andersen (Ed.), Doing sport psychology (pp. 17-31). Leeds, UK: Human Kinetics.

Gross, J. J., \& Thompson, R. A. (2007). Emotion regulation: conceptual foundations. In J. J. Gross (Ed.), Handbook of emotion regulation (pp. 3-24). New York: Guildford Press.

Guba, E. G., \& Lincoln, Y. S. (1994). Competing paradigms in qualitative research. In N. K. Denzin, \& Y. S. Lincoln (Eds.), Handbook of qualitative research (pp. 105-117). London, UK: Sage.

Hanin, Y. L. (2000a). Individual zones of optimal functioning (IZOF) model. In Y. L. Hanin (Ed.), Emotions in sport (pp. 65-89). Leeds, UK: Human Kinetics.

Hanin, Y. L. (2000b). Successful and poor performance and emotions. In Y. L. Hanin (Ed.), Emotions in sport (pp. 157-187). Leeds, UK: Human Kinetics.

Hanin, Y. L. (2000c). IZOF-based emotion-profiling: step-wise procedures and forms. In Y. L. Hanin (Ed.), Emotions in sport (pp. 303-313). Leeds, UK: Human Kinetics.

Hanin, Y. L. (2003). Performance related emotional states in sport: a qualitative analysis [48 paragraphs]. Forum Qualitative Sozialforschung/Forum. Qualitative Social Research, 4. http://nbn-resolving.de/urn:nbn:de:0114-fqs030151.

Hanin, Y. L. (2007). Emotions in sport: current issues and perspectives. In G.Tenenbaum., \& R. C. Eklund (Eds.), Handbook of sport psychology (3rd ed.). (pp. 31-58) Hobolen, NJ: Wiley \& Sons.

Hanin, Y. L. (2010). Coping with anxiety in sport. In A. R. Nicholls (Ed.), Coping in sport: Theory, methods, and related constructs (pp. 159-175). New York, NY: Nova Science.

Hanin, Y., \& Hanina, M. (2009). Optimization of performance in top-level athletes: an action-focused coping approach. International Journal of Sport Science \& Coaching, 4, 47-91. doi:10.1260/1747-9541.4.1.47.

Hanin, Y., \& Stambulova, N. B. (2002). Metaphoric description of performance states: an application of the IZOF model. The Sport Psychologist, 16, 396-415.

Hanin, Y., \& Syrjä, P. (1995). Performance affect in junior ice hockey players: an application of the Individual Zones of Optimal Functioning model. The Sport Psychologist, 9, 169-187.

Hardy, J., Roberts, R., \& Hardy, L. (2009). Awareness and motivation to change negative self-talk. The Sport Psychologist, 23, 435-450.

Harmison, R. J. (2006). Peak performance in sport: identifying ideal performance states and developing athletes' psychological skills. Professional Psychology: Research and Practice, 37, 233-243. doi:10.1037/0735-7028.37.3.233.

Huang, H. B. (2010). What is good action research?: why the resurgent interest? Action Research, 8, 93-109. doi:10.1177/1476750310362435.

Jackson, S. A. (2000). Joy, fun, and flow state in sport. In Y. L. Hanin (Ed.), Emotions in sport (pp. 135-155). Leeds, UK: Human Kinetics.

Jones, G. (1995). More than just a game: research developments and issues in competitive state anxiety in sport. British Journal of Psychology, 86, 449-478. doi:10.1111/j.2044-8295.1995.tb02565.x.

Jones, M. V. (2003). Controlling emotions in sport. The Sport Psychologist, 17, $471-486$.

Jones, G., Hanton, S., \& Swain, A. (1994). Intensity and interpretation of anxiety symptoms in elite and non-elite sports performers. Personality and Individual Differences, 17, 657-663. doi:10.1016/0191-8869(94)90138-4.

Jones, M. V., Mace, R. D., \& Williams, S. (2000). Relationship between emotional state and performance during international field hockey matches. Perceptual and Motor Skills, 90, 691-701. doi:10.2466/PMS.90.2.691-701.

Kellmann, M., \& Beckmann, J. (2003). Research and intervention in sport psychology: new perspectives on an inherent conflict. International Journal of Sport and Exercise Psychology, 1, 13-26.

Kingston, K. M., \& Hardy, L. (1997). Effects of different types of goals on processes that support performance. The Sport Psychologist, 11, 277-293.

Kiresuk, T. J., \& Sherman, R. E. (1968). Goal attainment scaling: a general method for evaluating comprehensive community mental health programs. Community Mental Health Journal, 4, 443-453. doi:10.1007/BF01530764.

Krauss, S. E. (2005). Research paradigms and meaning making: a primer. The Qualitative Report, 758-770.

Lang, P. J. (1979). A bio-informational theory of emotional imagery. Psychophysiology, 16, 495-512. doi:10.1111/j.1469-8986.1979.tb01511.x. 
Lang, P. J., Kozak, M. J., Miller, G. A., Levin, D. N., \& McLean, A., Jr. (1980). Emotional imagery: conceptual structure and pattern of somato-visceral response. Psychophysiology, 17, 179-192. doi:10.1111/j.1469-8986.1980.tb00133.x.

Lazarus, R. S. (2000). How emotions influence performance in competitive sports. The Sport Psychologist, 14, 229-252.

Lincoln, Y. S., \& Guba, E. G. (1985). Naturalistic inquiry. Newbury Park, CA: Sage.

Martin, G., \& Hrycaiko, D. (1983). Effective behavioral coaching: what's it all about? Journal of Sport \&' Exercise Psychology, 5, 8-20.

Mellalieu, S. D., Hanton, S., \& Fletcher, D. (2006). A competitive anxiety review: recent directions in sport psychology research. In S. Hanton, \& S. D. Mellalieu (Eds.), Literature reviews in sport psychology (pp. 1-45). New York, NY: Nova Science.

Mellalieu, S. D., Hanton, S., \& O'Brien, M. (2006). The effects of goal setting on rugby performance. Journal of Applied Behavior Analysis, 39, 257-261. doi:10.1901/ jaba.2006.36-05.

Miles, M. B., \& Huberman, A. M. (1994). Qualitative data analysis: An expanded sourcebook (2nd ed.). Thousand Oaks, CA: Sage Publishers. 172-205.

Moran, A. P. (1996). The psychology of concentration in sport performers: A cognitive analysis. Hove, UK: Psychology Press.

Murphy, S. M. (2000). Afterword. In M. B. Andersen (Ed.), Doing sport psychology (pp. 275-279). Leeds, UK: Human Kinetics.

Nieuwenhuys, A., Hanin, Y. L., \& Bakker, F. C. (2008). Performance-related experiences and coping during races: a case of an elite sailor. Psychology of Sport and Exercise, 9, 61-76. doi:10.1016/j.psychsport.2006.12.007.

Nieuwenhuys, A., Vos, L., Pijpstra, S., \& Bakker, F. C. (2011). Meta-experiences and coping effectiveness in sport. Psychology of Sport and Exercise, 12, 135-143. doi:10.1016/j.psychsport.2010.07.008

Noteboom, J. T., Fleshner, M., \& Enoka, R. M. (2001). Activation of the arousal response can impair performance on a simple motor task. Journal of Applied Physiology, 91, 821-831.

Petitpas, A. J., Giges, B., \& Danish, S. J. (1999). The sport psychologist-athlete relationship: implications for training. The Sport Psychologist, 13, 344-357.

Prapavessis, H., \& Grove, J. R. (1991). Precompetitive emotions and shooting performance: the mental health and zone of optimal function models. The Sport Psychologist, 5, 223-234.

Ravizza, K. (2006). Increasing awareness for sport performance. In J. M. Williams (Ed.), Applied sport psychology: Personal growth to peak performance (5th ed). (pp. 228-239). New York, NY: McGraw-Hill.
Robazza, C. (2006). Emotion in sport: an IZOF perspective. In S. Hanton, \& S. D. Mellalieu (Eds.), Literature reviews in sport psychology (pp. 127-158). New York, NY: Nova Science.

Robazza, C., \& Bortoli, L. (2003). Intensity, idiosyncratic content and functional impact of performance-related emotions in athletes. Journal of Sport Sciences, 21, 171-189. doi:10.1080/0264041031000071065.

Robazza, C., Bortoli, L., \& Nougier, V. (2000). Performance emotions in an elite archer: a case study. Journal of Sport Behavior, 23, 144-163.

Robazza, C., Pellizzari, M., \& Hanin, Y. (2004). Emotion self-regulation and athletic performance: an application of the IZOF model. Psychology of Sport and Exercise, 5, 379-404. doi:10.1016/S1469-0292(03)00034-7.

Ruiz, M., Hanin, Y. L., \& Robazza, C. (2011, September). Assessment of Performancerelated Psychobiosocial (PBS) State: an exploratory study. A poster presented at the Association for Applied Sport Psychology conference, Honolulu, HI.

Sharp, L., Woodcock, C., Holland, M. J. G., Duda, J. L., \& Cumming, J. (2010, October) Youth athletes' responses to a mental skills training program. Unpublished pape presented at the Association for Applied Sport Psychology conference, Providence, RI.

Simons, J. P., \& Andersen, M. B. (1995). The development of consulting practice in applied sport psychology: some personal perspectives. The Sport Psychologist, 9 449-468.

Tod, D., Iredale, F., \& Gillet, N. (2003). 'Psyching-up' and muscular force production Sports Medicine, 33, 47-58. doi:10.2165/00007256-200333010-00004.

Uphill, M. A., McCarthy, P. J., \& Jones, M. V. (2009). Getting to grip on emotion regulation in sport. In S. D. Mellalieu, \& S. Hanton (Eds.), Advances in applied sport psychology (pp. 162-194). Oxon, UK: Routledge.

Vallerand, R. J., \& Blanchard, C. M. (2000). The study of emotion in sport and exercise: Historical, definitional, and conceptual perspectives. In Y. L. Hanin (Ed.), Emotions in sport (pp. 3-37). Leeds, UK: Human Kinetics.

Vealey, R. S., \& Greenleaf, C. A. (2006). Seeing is believing: understanding and using imagery in sport. In J. M. Williams (Ed.), Applied sport psychology: Personal growth to peak performance (5th ed.). (pp. 306-348) New York, NY: McGrawHill.

Woodcock, C., Richards, H., \& Mugford, A. (2008). Quality counts: critical features for neophyte professional development. The Sport Psychologist, 22, 491-506.

Zinsser, N., Bunker, L., \& Williams, J. M. (2006). Cognitive techniques for building confidence and enhancing performance. In J. M. Williams (Ed.), Applied sport psychology: Personal growth to peak performance (5th ed.). (pp. 349-381) London, UK: McGraw Hill. 